\title{
New perspectives on ethnic segregation over time and space. A domains approach
}

\section{Maarten van Ham \& Tiit Tammaru}

To cite this article: Maarten van Ham \& Tiit Tammaru (2016): New perspectives on ethnic segregation over time and space. A domains approach, Urban Geography, DOI: 10.1080/02723638.2016.1142152

To link to this article: http://dx.doi.org/10.1080/02723638.2016.1142152 (c) 2016 The Author(s). Published by Taylor \&
Francis

曲 Published online: 07 Mar 2016.

Submit your article to this journal

Џ Article views: 243

Q View related articles ¿

View Crossmark data ¿ 


\title{
New perspectives on ethnic segregation over time and space. A domains approach
}

\author{
Maarten van $\mathrm{Ham}^{\mathrm{a}, \mathrm{b}}$ and Tiit Tammaru \\ aOTB - Research for the Built Environment, Faculty of Architecture and the Built Environment, Delft

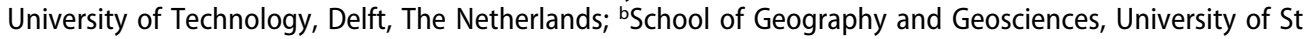 \\ Andrews, Fife, Scotland, UK; 'Division Centre for Migration and Urban Studies, Department of Geography, \\ University of Tartu, Tartu, Estonia
}

\begin{abstract}
Ethnic segregation has most often been studied at the place of residence, segregation being defined on the basis of the relative presence of different groups within city neighbourhoods. It is increasingly recognized, however, that segregation occurs in different ways in different domains (such as the workplace, leisure, social media, etc.), the residential domain being just one of many in which segregation can occur. In this research note we present the domains approach to segregation and outline some its conceptual, methodological and empirical underpinnings and challenges.
\end{abstract}

\section{ARTICLE HISTORY}

Received 25 September 2015 Accepted 15 December 2015

\section{KEYWORDS:}

Ethnic segregation; neighbourhood; domains; life course approach; time geography

When asked to give a definition of ethnic segregation most people will say something like "the uneven distribution of ethnic groups over neighbourhoods in a city". The term segregation has a strong connotation with residential neighbourhoods, and most studies investigating ethnic segregation focus on the urban mosaic of ethnic concentrations in residential neighbourhoods. However, there is now a small, but growing, literature, which focusses on segregation in other domains of daily life where inter-ethnic encounters and social interaction takes place, such as: working life (Bygren, 2013; Ellis, Wright, \& Parks, 2004, 2007; Glitz, 2014; Strömgren et al., 2014); family/partner relationship (Dribe \& Lundh, 2008; Haandrikman, 2014; Houston, Wright, Ellis, Holloway, \& Hudson, 2005; Kalmijn, 1998); leisure time (Kamenik, Tammaru, \& Toomet, 2015; Schnell \& Yoav, 2001; Silm \& Ahas, 2014a); education (Andersson, Osth, \& Malmberg, 2010; Malmberg, Andersson Eva, \& Bergsten, 2014; Reardon, Yun, \& McNulty Eitle, 2000) transport (Schwanen \& Kwan, 2012), and virtual domains such as social media (Joassart-Marcelli, 2014). There are hardly any studies which take into account multiple segregation domains and the links between them (Strömgren et al., 2014; Tammaru, Strömgren, Stjernström, \& Lindgren, 2010). This is mainly because of a lack of data tracking large numbers of people through space and time, and methods capable of analysing such data for multiple domains. This commentary argues that now better data is becoming available, there is a need for an integrated conceptual framework of ethnic segregation in different life domains. We therefore propose some first steps for the development of such a framework to better understand 
and measure ethnic segregation (see also Ellis, Wright, \& Parks, 2006; Marcińczak, Tammaru, Strömgren, \& Lindgren, 2015; Strömgren et al., 2014; Wang, 2010).

The interest in concentrations of ethnic groups in certain neighbourhoods of cities has different origins. Residential ethnic segregation is often seen as problematic since it might hamper the integration of ethnic minorities in society because of a lack of contact with the majority population. For example, the integration on the labour market is more successful among newly arrived immigrants if they live outside ethnic enclaves, although there are differences between subgroups based on city of residence, skills, gender, etc. (Edin, Fredricksson, \& Aslund, 2003; Hedberg \& Tammaru, 2010). The literature on neighbourhood effects suggests that otherwise similar individuals may experience different socio-economic outcomes depending on characteristics of the residential neighbourhood context (van Ham, 2012). A detailed study by Musterd, Andersson, Galster, and Kauppinen (2008) focused explicitly on the effects of living in ethnic concentration neighbourhoods, and found that immigrants living together with co-ethnics have significantly lower incomes compared to immigrants living in non-ethnic neighbourhoods.

The focus on residential segregation is understandable. Ethnic residential segregation is easily visible in cities as segregated neighbourhoods often have their own distinct identity and reputation (Permentier, van Ham, \& Bolt, 2007, 2009). Simply walking through a city can give the observer information about the levels of ethnic segregation in neighbourhoods, especially if there are many visible ethnic minorities present. Residential segregation is also relatively easy to investigate by using register or census data on where different ethnic groups live. For most people the residence is "fixed" in space and changes over time are registered by governments and other institutions. Another reason for the interest in ethnic residential segregation is that the spatial concentration of ethnic minorities is often a signal of accumulated problems in neighbourhoods because the strong overlap between ethnicity and socio-economic status (Malmberg et al., 2014).

However, if the interest in segregation stems from the idea that we want to measure the integration of ethnic minorities in society, and from an interest in social interaction between ethnic groups, then just investigating where people live is far too limited (Kamenik et al., 2015; Schnell \& Yoav, 2001; Wellman, 1996). Home is still the main anchor point of our daily activities (Silm \& Ahas, 2014a). Home is mostly where we start and end our day and we spend a significant share of our time in the neighbourhood where we live. The residential neighbourhood also reflects our socio-economic status through the cost of housing we are able to pay. Neighbourhoods are also still important places of social interaction, especially for some groups such as ethnic minorities, elderly people, children, and the socio-economically less well-off (Van Kempen \& Wissink, 2014). But, the residential neighbourhood is only one of many domains of our lives in which we meet others and segregation is not just limited to residential neighbourhoods. Moreover, there are important links between spatial segregation and the ways that social networks operate. For example, informal and a-spatial hiring and job finding networks might produce ethnically segregated workplaces.

Schnell and Yoav (2001) proposed a conceptual model that includes three dimensions of segregation. The first dimension is residential segregation, which represents choices made by or forced upon people in terms of their housing location. The two 
other dimensions include daily activity space and social interaction. Activity space represents the locations in which people perform the routines of their daily livesincluding the sites individuals visit for employment, education, entertainment, recreation-while social interactions represent the choices made by or forced upon people when they develop their social networks. In this paper we build on Schnell and Yoav (2001) and suggest a conceptual model ${ }^{1}$ of ethnic segregation which combines elements from the life course approach and from time geography.

\section{Domains approach to ethnic segregation}

Most studies that investigate segregation in other domains than the residential neighbourhood, investigate these domains in isolation, or at best pairwise (Pendakur, Pendakur, \& Bevelander, 2015), although there are some exceptions (Strömgren et al., 2014). We argue that in order to come to a fuller understanding of segregation, we need to investigate not only multiple domains simultaneously, but we also need to investigate the linkages and interactions between these domains over space and time, as well as between spatial domains and social networks. This requires a new approach which does not only investigate the correlations between segregation in different domains, but tries to understand the common underlying factors. The correlation between segregation in different domains is not a statistical nuisance to be modelled away, but has substantial social relevance in its own right, for example for the development of policy to counter segregation. Central in our argument is that a domains approach to understanding ethnic segregation should be longitudinal in nature. The conception of time is important as there are daily, weekly, monthly, yearly and life-time interactions between the different life domains (Silm \& Ahas, 2014b). There is also evidence that segregation has an intergenerational dimension which also applies to ethnicity (Hedman, Manley, van Ham, \& Östh, 2015; Sharkey, 2008; Tammaru \& Kontuly, 2010; van Ham, Hedman, Manley, Coulter, \& Östh, 2014).

Consider, and compare, the following fictional examples of people from minority ethnic backgrounds living their lives in various domains linked over time and space. X, female and first generation immigrant, lives in an ethnic concentration neighbourhood. She has no formal education, and her husband, who is currently unemployed, is a second-generation immigrant from the same ethnic background. Their two children go to a local school which is highly ethnically segregated and their friends mainly have an ethnic minority background. X travels to work in the city centre every day at 5:30 by underground rail, where the majority of fellow travellers also have an ethnic minority background. She works as a cleaner in a large bank where her main social interactions are with other people with an ethnic minority background. X and her family live in a similar segregated neighbourhood as where her husband grew up with his parents.

$\mathrm{Y}$, female, and a second generation immigrant, has obtained a higher education degree and lives together with her partner who is a member of the majority population. They met at school and now have two children. They live in a majority population dominated suburb and their children go to a local school with mainly children from the majority population. $\mathrm{Y}$ works in a company with a mixed ethnic makeup in the city centre and travels there by train during rush hour. She spends her free time with friends from school and work with mixed ethnic backgrounds, and she spends time with her 
own family and the family of her partner. $\mathrm{Y}$ and her partner often travel to her grandparents abroad for family visits and to familiarize her children with their cultural background.

$\mathrm{Z}$, who is a single male, is a second generation immigrant and lives in the city centre in a neighbourhood with many young urban singles and couples from the majority group. He went to university and works in another part of town as a lawyer in a company where he is the only staff member with an ethnic minority background. He travels to work by car. Most of his friends are from the majority population and he meets them in his spare time. $\mathrm{Z}$ visits his parents who live in an ethnic concentration neighbourhood in another city every few months.

These three fictional examples illustrate that the lives of ethnic minority group members can be very diverse. Not just in terms of the neighbourhoods they live in, but also in terms of who they live with, where they work, who they meet on their way to work, at work, in their leisure time, etcetera. Their residential neighbourhoods alone do not capture the level of segregation they experience in their daily lives. Now consider one additional example which potentially links the cases of $\mathrm{X}, \mathrm{Y}$, and Z. Consider $\mathrm{Q}$, who is a majority population male, and who works as an executive in the bank where $\mathrm{X}$ cleans. Even though they sometimes briefly share the same spaces at work, they have never spoken with each other. Q works in the building next to the office where Y works, but because $\mathrm{Q}$ always travels to work by car, parks underground and hardly ever visits the public space outside his office, he has never met $Y$. Q does meet $Z$ on a regular basis as $\mathrm{Z}$ offers legal advice to the bank where $\mathrm{Q}$ works. So, $\mathrm{Q}$ visits the same spaces as $\mathrm{X}, \mathrm{Y}$, and $\mathrm{Z}$, but only really interacts with one of them.

These examples illustrate not only the importance of the various domains, but also the importance of daily, weekly, monthly, and life time-space paths. The examples also show that the causal relationships between segregation in different domains of daily life can be complicated and multi-directional. People might find their partner through work, or find their job through their partner; contacts in the neighbourhood might lead to job opportunities, or housing in a particular neighbourhood can be found through a work colleague. People might lead completely segregated lives in one domain, and completely integrated lives in another. People might share the same spaces, at the same time, but never meet or interact.

\section{Conceptual framework of the domains approach}

We argue that a conceptual framework of a domains approach to segregation should include elements of both time and space paths (see Figure 1). We therefore propose a framework which combines elements from the life course approach (Elder, 1985; Feijten, 2005; Kulu \& González-Ferrer, 2014; Mulder \& Hooimeijer, 1999) and from time geography by Hägerstrand (1970; see also Neutens et al., 2011; Pred, 1977, 1981): a domains approach to ethnic segregation over time and space.

The life course approach offers a dynamic framework to understand residential mobility and location choice (Schaake, Burgers, \& Mulder, 2014; van Ham, 2012). Within the life course framework people lead parallel and interrelated careers in different domains of life, such as housing, education, employment and household/ family. Events in one career influence events in other careers through (changing) 


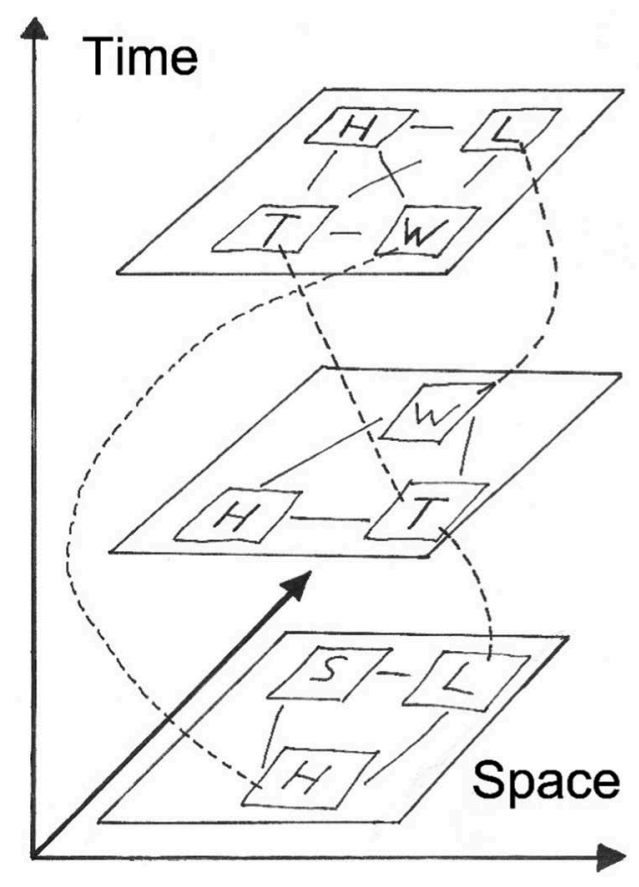

Figure 1. Conceptual framework of a domains approach to ethnic segregation over time and space $(\mathrm{H}=$ home; $\mathrm{L}=$ Leisure; $\mathrm{W}=$ work; $\mathrm{S}=$ school; $\mathrm{T}=$ travel). Source: authors.

preferences, resources (such as income) and constraints. The various careers of an individual do not only interact with each other, but also with the careers of other individuals (such as household members). The effects of the careers on mobility and location choices are mediated by the changing social, political, institutional, and spatial context, which offers both opportunities and constraints. Strömgren et al. (2014) found for Sweden that low levels of residential segregation reduces workplace segregation, and that being intermarried with a native reduces workplace segregation for immigrant men but not for immigrant women. A major notion in the life-course approach is that the situation at a certain moment in the life course can only be understood if past life events and their interdependencies are taken into account (Kulu \& Washbrook, 2014). For example, van Ham et al. (2014) found for Sweden that the socio-economic composition of the neighbourhood children lived in before they left the parental home is strongly related to the status of the neighbourhood they live in much later in life, especially for ethnic minorities.

Time geography as coined by Hägerstrand (1970) stresses the importance of time in understanding human activity: "... time has a critical importance when it comes to fitting people and things together for functioning in socio-economic systems ..." (Hägerstrand, 1970, p. 10). Hägerstrand introduced the concept of a space-time path which represents the way an individual navigates through the spatial-temporal environment. The space-time path is the sum of all places visited (and people met) during a given time frame, and is shaped by both individual action and institutional contexts, ranging from urban policies shaping segregation, initiatives related to workplace 
diversity, down to the opening hours of leisure time facilities shaping when and where people can spend their free time. The temporal rhythms and related segregation patterns across time vary a lot by hour, weekday, season, and year, while encounters vary a lot by geographic scale and places, ranging from home through neighbourhood and district to city and ex-urban levels (Fowler, 2015; Silm \& Ahas, 2014a)

While the life course approach focuses on the temporal dimension of linked and interacting parallel life careers in various domains, time geography has both time and space as its main constitutional elements. Figure 1 illustrates the interaction between the most important domains (denoted by the letters) for understanding ethnic segregation within a space-time framework. Individuals have various parallel careers in a range of domains. Each of these domains interact through time and space, on the level of individuals, households and wider (spatial and a-spatial) social networks. During the course of a day, week, month and life time, people move through space and meet people from different ethnic backgrounds in different domains. Segregation can be understood on the level of the domains and on the level of individuals. For each domain segregation can be understood as the distribution of ethnic groups over neighbourhoods, schools, workplaces etcetera, at various places and moments in time. Segregation can also be understood on the level of individuals. Individuals can be compared with regard to the sum of interactions with other ethnic groups over time and space (weighted by, for example, duration of the interaction). The sum of these interactions (cf. Toomet, Silm, Saluveer, Ahas, \& Tammaru, 2015) gives an idea of the level of ethnic segregation an individual experiences over a period of time.

A major challenge for the approach is to identify the structural mechanisms which will lead to the connections between the domains. A major structural mechanism will be social class, which affects the rhythm of daily life, the places we visit and the people we meet. Social class also affects who we partner with, our job finding networks, and the people we meet in our leisure time. Other important factors influencing the links between the different domains are level of education, household composition (the presence of partner and children, and the age of children), and off course the ethnic composition of the spatial and social environments we frequent. Likewise, the willingness and ability (e.g. host county language proficiency) to integrate of minorities will be an important underlying factor that shapes the integration pathways of immigrants across domains.

\section{Research design for a domains approach to ethnic segregation}

The domains approach to ethnic segregation requires researchers to formulate new hypotheses about the interactions between domains over time and space. In order to investigate ethnic segregation across multiple domains, spaces, and time frames, we need integrated, time-flexible and space-flexible longitudinal approaches to data collection and analysis. The current lack of such data is a major hurdle in the empirical application of the conceptual framework suggested. However, the increasing availability of longitudinal register data that links various domains (Strömgren et al., 2014) and mobile positioning data (Silm \& Ahas, 2014a, 2014b) allow for new and innovation empirical segregation research. Where ethnic segregation at the level of neighbourhoods is easy to measure as residential locations are relatively fixed, the proposed domains 
approach to ethnic segregation requires more flexible time-space path measurements of segregation on various time scales (daily, weekly, monthly, yearly, and life-time). The domains approach requires rich longitudinal data on the time-space paths of individuals for multiple domain variables, such as places of residence, schools, places of work, and places where people spend their free time.

Within-domain segregation change-changing levels of segregation within a domain of an individual-can occur because (a) the individual moves to another neighbourhood, workplace, school, etcetera, or (b) other people move around, reshaping the domain context of a given individual. Promising research which explores the dimensions of domain change has recently emerged (Ellis et al., 2004; Silm \& Ahas, 2014a; Strömgren et al., 2014; Toomet et al., 2015). Between-domain segregation change can take place because people move to another domain (for example, from the residential neighbourhood to work or school) with a different level of ethnic segregation. From a domains perspective it is especially interesting to investigate whether the level of ethnic segregation in one domain also influences the level of segregation in another domain (see Pendakur et al., 2015; Strömgren et al., 2014). Testing a hypothesis such as whether or not living in a mixed ethnic residential neighbourhood leads to working in a mixed-ethnic workplace requires following individual domain pathways (or sequences) over time, using longitudinal data on within- and between-domain mobility. Following domain pathways will provide valuable insights in processes of integration of ethnic minority groups. What kind of domain pathways, such as intermarriage leading to residential integration, leading to workplace integration, would be the most common? And how do these pathways vary by ethnic groups, their migration backgrounds, individual characteristics, and over time? Even though it will be difficult to identify causal relationships, identifying the most common sequences in a longitudinal framework (cf. Blossfeld, Golsch, \& Rohwer, 2007) is an important step towards explanation.

Recent developments in mobile phone tracking allows researchers to even let go of domain pathways and to investigate true detailed continuous time-space pathways of different ethnic groups and how these interact over time and space (see for example Silm \& Ahas, 2014a). Combined with register and survey data, such mobile phone data opens up a whole new world of understanding ethnic processes in cities, which should be accompanied by discussions on research ethics. This allows researchers to move away from home and workplace based studies of residential segregation, and to include leisure time activities and transport explicitly into the segregation research agenda (Toomet et al., 2015). Using true time-space pathways allows researchers to trace the exact paths of people in cities, including where different ethnic groups spend their weekends, summer holidays, which events they visit etcetera. Furthermore, linking call data (to whom people call) with spatial data (time-space paths of people in the city) would open up new research opportunities in merging segregation research with social network analysis, linking spatial and social network research. Even one step further, these developments in data availability could lead to new cumulative measures of exposure to other ethnic groups over longer periods of time in a similar way as has been suggested for the creation of an "exposome" by epidemiologists, which encompasses life-course environmental exposures from the prenatal period onwards (Wild, 2005). 


\section{Note}

1. The domains approach to ethnic segregation can easily be adapted to other forms of segregation such as socio-economic segregation. Investigating socio-economic segregation requires an even more flexible approach as people can change their socio-economic position.

\section{Disclosure statement}

No potential conflict of interest was reported by the authors.

\section{Funding}

The research leading to these results has received funding from the European Research Council under the European Union's Seventh Framework Programme (FP/2007-2013)/ERC [Grant Agreement No. 615159] (ERC Consolidator Grant DEPRIVEDHOODS, Socio-spatial inequality, deprived neighbourhoods, and neighbourhood effects); from the Marie Curie programme under the European Union's Seventh Framework Programme (FP/2007-2013)/Career Integration [Grant No. PCIG10-GA-2011-303728] (CIG Grant NBHCHOICE, Neighbourhood choice, neighbourhood sorting, and neighbourhood effects), from the Estonian Research Council (Institutional Research Grant IUT2-17 on Spatial Population Mobility and Geographical Changes in Urban Regions); and from the Estonian Science Foundation [Grant Nos. 8774 and 9247].

\section{References}

Andersson, Eva K., Osth, John, \& Malmberg, Bo (2010). Ethnic segregation and performance inequality in the Swedish school system: A regional perspective. Environment and Planning A, 42(11), 2674-2686.

Blossfeld, Hans-Peter, Golsch, Katrin, \& Rohwer, Götz (2007). Event history analysis with stata. London: LEA.

Bygren, Magnus (2013). Unpacking the causes of ethnic segregation across workplaces. Acta Sociologica, 56(1), 3-19.

Dribe, Martin, \& Lundh, Christer (2008). Intermarriage and immigrant integration in Sweden: An exploratory analysis. Acta Sociologica, 51(4), 329-354.

Edin, Per Anders, Fredricksson, Peter, \& Aslund, Olof (2003). Ethnic enclaves and the economic success of immigrants: Evidence from a natural experiment. Quarterly Journal of Economics, $118(1), 329-357$.

Elder, Glen H. (1985). Perspectives on the life course. In Glen H. Elder (Ed.), Life course dynamics: Trajectories and transitions, 1968-1980 (pp. 23-49). Ithaca, NY: Cornell University Press.

Ellis, Mark, Wright, Richard, \& Parks, Virginia (2004). Work together, live apart? Geographies of racial and ethnic segregation at home and at work. Annals of the Association of American Geographers, 94(3), 620-637.

Ellis, Mark, Wright, Richard, \& Parks, Virginia (2006). The immigrant household and spatial assimilation: partnership, nativity, and neighborhood location. Urban Geography, 27(1), 1-19.

Ellis, Mark, Wright, Richard, \& Parks, Virginia (2007). Geography and the immigrant division of labour. Economic Geography, 83(3), 255-281.

Feijten, Peteke (2005). Life events and the housing career: A retrospective analysis of timed effects. Delft: Eburon.

Fowler, Christopher S. (2015). Segregation as a multiscalar phenomenon and its implications for neighborhood-scale research: The case of south Seattle 1990-2010. Urban Geography. Retrieved from http://www.tandfonline.com/doi/abs/10.1080/02723638.2015.1043775

Glitz, Albrecht (2014). Ethnic segregation in Germany. Labour Economics, 29, 28-40. 
Haandrikman, Karen (2014). Binational marriages in Sweden: Is there an EU effect? Population, Space and Place, 20(2), 177-199.

Hägerstrand, Torsten (1970). What about people in regional science? Papers of the Regional Science Association, 24, 7-21.

Hedberg, Charlotta, \& Tammaru, Tiit (2010). 'Neighbourhood effects' and 'city effects': Immigrants' transition to employment in Swedish large city-regions (SULCIS Working Papers 6). Stockholm: University Linnaeus Center for Integration Studies.

Hedman, Lina, Manley, David, van Ham, Maarten, \& Östh, John (2015). Cumulative exposure to disadvantage and the intergenerational transmission of neighbourhood effects. Journal of Economic Geography, 15(1), 195-215.

Houston, Serin, Wright, Richard, Ellis, Mark, Holloway, Steven, \& Hudson, Margaret (2005). Places of possibility: Where mixed-race partners meet. Progress in Human Geography, 29(6), 700-717.

Joassart-Marcelli, Pascale (2014). Gender, social network geographies, and low-wage employment among recent Mexican immigrants in Los Angeles. Urban Geography, 35(6), 822-851.

Kalmijn, Matthijs (1998). Intermarriage and homogamy: Causes, patterns, trends. Annual Review of Sociology, 24, 395-421.

Kamenik, Kristiina, Tammaru, Tiit, \& Toomet, Ott (2015). Ethnic segmentation in leisure time activities in Estonia. Leisure Studies, 34(5), 566-587.

Kulu, Hill, \& González-Ferrer, Amparo (2014). Family dynamics among immigrants and their descendants in Europe: Current research and opportunities. European Journal of Population, 30(4), 411-435.

Kulu, Hill, \& Washbrook, Elizabeth (2014). Residential context, migration and fertility in a modern urban society. Advances in Life Course Research, 21(3), 168-182.

Malmberg, Bo, Andersson Eva, K., \& Bergsten, Zara (2014). Composite geographical context and school choice attitudes in Sweden: A study based on individually defined, scalable neighborhoods. Annals of the Association of American Geographers, 104(4), 869-888.

Marcińczak, Szymon, Tammaru, Tiit, Strömgren, Magnus, \& Lindgren, Urban (2015). Changing patterns of residential and workplace segregation in the Stockholm metropolitan area. Urban Geography, 36(7), 969-992.

Mulder, Clara, \& Hooimeijer, Pieter (1999). Residential relocations in the life course. In J. G. van Wissen Leo \& Pearl A. Dykstra (Eds.), Population issues: An interdisciplinary focus (pp. 159 -186). Den Haag: NIDI.

Musterd, Sako, Andersson, Roger, Galster, George, \& Kauppinen, Timo (2008). Are immigrants' earnings influenced by the characteristics of their neighbours? Environment and Planning A, 40(4), 785-805.

Neutens, Tijs, Schwanen, Tim, \& Witlox, Frank (2011). The prism of everyday life: Towards a new research agenda for time geography. Transport Reviews, 31(1), 25-47.

Pendakur, Krishna, Pendakur, Ravi, \& Bevelander, Pieter. (2015). Are residential and workplace concentration correlated for immigrants? Evidence for Sweden. Journal of International Migration and Integration. Retrieved from http://link.springer.com/article/10.1007\% 2Fs12134-015-0430-4

Permentier, Matthieu, van Ham, Maarten, \& Bolt, Gideon (2007). Behavioural responses to neighbourhood reputations. Journal of Housing and the Built Environment, 22(2), 199-213.

Permentier, Matthieu, van Ham, Maarten, \& Bolt, Gideon (2009). Neighbourhood reputation and the intention to leave the neighbourhood. Environment and Planning A, 41(9), 2162-2180.

Pred, Allan R. (1977). City systems in advanced economies: Past growth, present processes, and future development options. New York, NY: John Wiley \& Sons.

Pred, Allan R. (1981). Social reproduction and the time-geography of everyday life. Geografiska Annaler Series B Human Geography, 63(1), 5-22.

Reardon, Sean F., Yun, John T., \& McNulty Eitle, Tamela (2000). The changing structure of school segregation: Measurement and evidence of multiracial metropolitan-area school segregation, 1989-1995. Demography, 37(3), 351-364.

Schaake, Karina, Burgers, Jack, \& Mulder, Clara (2014). Ethnicity, education and income, and residential mobility between neighbourhoods. Journal of Ethnic and Migration Studies, 40(4), 512-527. 
Schnell, Izhak, \& Yoav, Benjamini (2001). The sociospatial isolation of agents in everyday life spaces as an aspect of segregation. Annals of the Association of American Geographers, 91(4), 622-636.

Schwanen, Tim, \& Kwan, Mei-Po (2012). Critical space-time geographies. Environment and Planning A, 44(9), 2043-2048.

Sharkey, Patrick (2008). The intergenerational transmission of context. American Journal of Sociology, 113(4), 931-969.

Silm, Siiri, \& Ahas, Rein (2014a). Ethnic differences in activity spaces: A study of out-of-home nonemployment activities with mobile phone data. Annals of the Association of American Geographers, 104(3), 542-559.

Silm, Siiri, \& Ahas, Rein (2014b). The temporal variation of ethnic segregation in a city: Evidence from a mobile phone use dataset. Social Science Research, 47, 30-43.

Strömgren, Magnus, Tammaru, Tiit, Danzer, Alexander M., van Ham, Maarten, Marcinczak, Szymon, Stjernström, Olof, \& Lindgren, Urban (2014). Factors shaping workplace segregation between natives and immigrants. Demography, 51(2), 645-671.

Tammaru, Tiit, \& Kontuly, Thomas (2010). Selectivity and destinations of ethnic minorities leaving main gateway cities in Estonia. Population Space and Place, 17(5), 674-688.

Tammaru, Tiit, Strömgren, Magnus, Stjernström, Olof, \& Lindgren, Urban (2010). Learning through contact? The effects on earnings of immigrant exposure to the native population. Environment and Planning A, 42(12), 2938-2955.

Toomet, Ott, Silm, Siiri, Saluveer, Erki, Ahas, Rein, \& Tammaru, Tiit. (2015). Where do EthnoLinguistic groups meet? How copresence during free-time is related to copresence at home and at work. PLoS One. Retrieved from http://journals.plos.org/plosone/article?id=10.1371/ journal.pone.0126093

van Ham, Maarten. (2012). Housing behaviour. In David Clapham, William A. V. Clark, \& Kenneth Gibb (Eds.), Handbook of Housing Studies. London: Sage. (chapter 3)

van Ham, Maarten, Hedman, Lina, Manley, David, Coulter, Rory, \& Östh, John (2014). Intergenerational transmission of neighbourhood poverty. An analysis of neighbourhood histories of individuals. Transactions of the Institute of British Geographers, 39(3), 402-417.

Van Kempen, Ronald, \& Wissink, Bart (2014). Between places and flows: Towards a new agenda for neighbourhood research in an age of mobility. Geografiska Annaler: Series B Human Geography, 96(2), 95-108.

Wang, Qingfang (2010). How does geography matter in the ethnic labor market segmentation process? A case study of Chinese immigrants in the San Francisco CMSA. Annals of the Association of American Geographers, 100(1), 182-201.

Wellman, Barry (1996). Are personal communities local? A Dumptarian reconsideration. Social Networks, 18(4), 347-354.

Wild, Christopher Paul (2005). Complementing the genome with an "exposome": The outstanding challenge of environmental exposure measurement in molecular epidemiology. Cancer Epidemiology, Biomarkers \& Prevention, 14(8), 1847-1850. 